Home mechanical ventilation

\title{
Risk management of the home ventilator dependent patient
}

\section{A K Simonds}

\section{Who is responsible for minimising risks to patients receiving ventilatory support in the home?}

\begin{abstract}
A headline from The Times newspaper of 14 August $2000^{1}$ - "Power cut kills man on home ventilator"-is likely to strike a chill in the heart of anyone involved in providing home respiratory care. Bearing in mind it is impossible to guarantee complete safety even in the hospital environment, what is the respiratory practitioner's responsibility towards the individual receiving ventilatory support in the home, and how can these risks be minimised?
\end{abstract}

\section{EXTENT OF THE PROBLEM}

The recent Eurovent study ${ }^{2}$ showed that there are around 21500 individuals receiving home ventilation in Europe: about one third have neuromuscular conditions, one third parenchymal lung disease (mainly COPD), and the remainder have chest wall disorders (scoliosis, thoracoplasty, obesity hypoventilation syndrome); $13 \%$ use tracheostomy ventilation and around $10 \%$ are in the paediatric age range. Although the prevalence of home ventilation varies considerably, in nearly all regions there is a rapid growth in those receiving home non-invasive ventilation (NIV).

One of the difficulties in assessing the extent of ventilator related complications in the home/community is that in most countries there is no centralised database, and even where equipment failure is recorded the consequences of the malfunction for the patient are not clear. Further information on quality control of ventilator care in the home from the Eurovent survey has shown that only $56 \%$ of hospitals initiating home ventilation assessed whether patients or caregivers cleaned and operated the ventilatory equipment correctly after discharge from hospital, and even fewer centres $(25 \%)$ were aware of a vigilance system for reporting adverse events or mechanical failure. Ventilator servicing was carried out by external equipment companies in many countries, but in general there was wide variation in provision. ${ }^{2}$ In some countries such as France and Denmark home care is comprehensive and well organised $^{4}$ while, in others, funding for the home equipment is problematical, let alone continuing support in the community.

In a US study Srinivasan et $a l^{5}$ surveyed the frequency, causes, and outcome of home ventilator failure over 1 year in 150 adult and paediatric ventilator assisted individuals of whom $76 \%$ received ventilation via a tracheostomy. The majority had neuromuscular disease including 34\% with quadriplegia, and $46 \%$ required 24 hour ventilatory support. 189 cases of suspected ventilator failure were reported per 840000 hours of assisted ventilation (or one failure for every 1.25 years of continuous ventilator use). Notably, the more vulnerable 24 hour ventilator dependent patients were more likely to experience problems (66\% of incidents), but when this figure was adjusted for hours of use the rate was similar to those using part time ventilation. Episodes of failure occurred in $28 \%$ of those receiving night time and part daytime ventilation, and in only $6 \%$ in those requiring support solely during sleep. Mechanical failure or defective equipment was present in 73 of the 189 incidents (39\%). Improper care, damage, or misuse by caregivers was felt to be responsible in 13\%, no problem could be identified in 16\%, and in a proportion the equipment was functioning but a change in the patient's condition had been misinterpreted as ventilator malfunction. It is important to note that maladjustment of settings and improper use were not thought to be malicious but due to problems with caregiver education. Immediate correction of the problem was achieved by replacing the ventilator in $44 \%$, repairing a malfunctioning part in $6 \%$, and adjusting ventilator settings in $21 \%$. Crucially, only two patients required admission to hospital and no deaths or serious injury resulted. Of particular relevance is the fact that home support in these patients was provided by a branch of the National Medical Homecare system and many patients had professional caregivers; also all individuals who were 24 hour ventilator dependent or lived more than 1 hour from the respiratory homecare company were given a second back-up ventilator in the home. No detail was given of the types of ventilator used or the nature of mechanical faults.

In this issue of Thorax Farré et $a l^{6}$ have examined the performance of home ventilators in a quality control study of 300 patients in Barcelona. A much smaller proportion of these patients required tracheostomy ventilation $(4.3 \%)$ or were 24 hour dependent (1.3\%) than in the US study, but this is probably representative of current proportions in Europe. The majority had chest wall or neuromuscular disease and received nocturnal non-invasive ventilation. Home mechanical ventilation was initiated in several hospitals and domiciliary ventilator care provided by four different homecare companies. The authors examined whether the ventilator settings in the home matched those prescribed at hospital set-up, the performance of the ventilator in delivering the preset volume and pressure, and tested the function of the ventilator alarms. They found a mismatch between prescribed and actual delivered pressure or volume of approximately $10 \%$. Alarms for power failure and circuit obstruction (high pressure) failed in $0.9 \%$ and $5.1 \%$ of ventilators respectively but, disconcertingly, disconnection alarms did not work in 52 (18.6\%). Clearly, failure of disconnection alarms is likely to be more serious in patients with very little breathing autonomy, and may also have adverse consequences during sleep. However, the authors found no link between ventilator performance or alarm problems and the number of hospital admissions in the year before the study. Ventilator compliance and subjective factors such as tolerance, interface issues, side effects, and quality of life which might affect ventilator use were not assessed.

\section{RISK MANAGEMENT}

At first sight the results of the study by Farré et $a l^{6}$ highlight discrepancies in settings and alarms but are relatively reassuring in that there were apparently few significant adverse consequences for patients. However, from a comprehensive risk management perspective, this misses the point. Ventilators can break down but mechanical failure is infrequent and predictable. Ventilator users, carers, and their interaction with the ventilator, on the other hand, are not. Herein lies the problem-a key part of any home care programme should be education of patients, families, and carers to help them use the equipment confidently and safely and to have a 
sensible plan of action once a problem arises.

Good communication and a structured discharge plan adapted to the individual are required. The patient and/or carers should complete competency training on how to operate the equipment, identify simple problems, and when to seek advice. Educational materials are now widely available. Arrangements are necessarily more complex in patients who are dependent on tracheostomy ventilation. Here there are additional risks associated with the tracheostomy which can become blocked, displaced or fall out, and because those receiving ventilation via a tracheostomy often have little or no spontaneous breathing capacity. Tracheostomy care and safe suctioning, as well as ventilator operation, need to be taught before discharge. Deterioration in respiratory function and increased ventilator dependency is inevitable in patients with motor neurone disease/amyotrophic lateral sclerosis (MND/ALS) and will occur over a slower period in conditions such as Duchenne muscular dystrophy. Safety considerations need to evolve with the course of the underlying disease. ${ }^{7}$ The potential problems and solutions are shown in table 1.

Ventilator users need telephone access to a team member, hospital ward, or service that they can contact at all times. Frequent callouts are an indication for medical review to assess disease state and appropriateness of ventilator settings, in addition to a check on ventilator performance. Helping patients and carers to recognise medical problems such as early signs of a chest infection will allow them to seek prompt medical review or to start a reserve course of antibiotics, escalate bronchodilator treatment, etc. Home surveillance using videophone monitoring of highly ventilator dependent patients and modem transmission of oximetry has been reported ${ }^{9}$ but use of these high technology approaches is not widespread. A limited number of patientsincluding some 24 hour ventilator dependent children-benefit from detailed evaluation of ventilation with $\mathrm{SaO}_{2}$ and $\mathrm{CO}_{2}$ home monitors, but highly unstable patients are not suitable for home care and nocturnal NIV users do not need this level of supervision. Clearly, detailed home monitoring is pointless if it does not inform or

\section{Table 1 Risk management considerations}

\begin{tabular}{|c|c|c|}
\hline Problem & Consequence & Risk management \\
\hline $\begin{array}{l}\text { Power failure, } \\
\text { e.g. power cut }\end{array}$ & Ventilator failure & $\begin{array}{l}\text { Mains power alarm. Battery back-up (internal or } \\
\text { external battery in circuit). Ambu bag with } \\
\text { connector for ventilator dependent patient. }\end{array}$ \\
\hline $\begin{array}{l}\text { Ventilator } \\
\text { malfunction }\end{array}$ & Ventilator failure & $\begin{array}{l}\text { Regular service and planned preventative } \\
\text { maintenance. Emergency contact line to report } \\
\text { problems. Back-up ventilator in patients with less } \\
\text { than one night ventilator free time. }\end{array}$ \\
\hline $\begin{array}{l}\text { Accidental } \\
\text { disconnection }\end{array}$ & $\begin{array}{l}\text { Failure of } \\
\text { ventilation }\end{array}$ & $\begin{array}{l}\text { Low pressure and low minute volume alarms. } \\
\text { Secure attachment of ventilator/circuitry } \\
\text { connections. Support of ventilator tubing to } \\
\text { prevent dragging on tracheostomy or mask. }\end{array}$ \\
\hline Circuit obstruction & $\begin{array}{l}\text { Failure, or suboptimal } \\
\text { ventilation }\end{array}$ & High pressure alarm. \\
\hline Mask fit & Too tight: pressure sore & $\begin{array}{l}\text { Close attention to mask fit, variety of interfaces to } \\
\text { alternate. Skin protective dressing. }\end{array}$ \\
\hline & Too loose: leaks & Low pressure, low minute volume alarms \\
\hline $\begin{array}{l}\text { Tracheostomy } \\
\text { blocked }\end{array}$ & $\begin{array}{l}\text { Failure of } \\
\text { ventilation }\end{array}$ & $\begin{array}{l}\text { Efficient suction with battery power or manual } \\
\text { operation. Carers trained to change } \\
\text { tracheostomy. Effective humidification. High } \\
\text { pressure alarm. }\end{array}$ \\
\hline $\begin{array}{l}\text { Tracheostomy falls out } \\
\text { or cannot be replaced } \\
\text { after changing }\end{array}$ & $\begin{array}{l}\text { Failure of } \\
\text { ventilation }\end{array}$ & $\begin{array}{l}\text { Improve fixation of tube. Carers trained to } \\
\text { change tube, smaller size tracheostomy tube } \\
\text { available. Ambu bag and mask available which } \\
\text { carers can use. }\end{array}$ \\
\hline Medical problems & $\begin{array}{l}\text { Acute deterioration, } \\
\text { settings no longer } \\
\text { appropriate }\end{array}$ & $\begin{array}{l}\text { Rapid access to advice. Carers and patients } \\
\text { trained to recognise early signs of chest infection } \\
\text { or ventilatory decompensation. Carers trained in } \\
\text { basic life support. Immediate access to hospital } \\
\text { care. Battery powered ventilator to use in transit. }\end{array}$ \\
\hline General & & $\begin{array}{l}\text { Patients and carers competent in ventilator } \\
\text { operation, basic maintenance, problem solving, } \\
\text { and when to seek help. Written plan of action for } \\
\text { predictable problems such as power cuts, chest } \\
\text { infection, and equipment failure. Equipment } \\
\text { problems notified to manufacturer and central } \\
\text { agency where available, e.g. Medicines and } \\
\text { Healthcare Products Regulatory Agency (MHRA). }\end{array}$ \\
\hline
\end{tabular}

enhance care. Conveniently, newer ventilators now provide increasing amounts of information that can be downloaded by smart card. These may identify problems such as leaking, insufficient inspiratory pressure, or an inappropriate back-up rate which can be easily remedied. Further developments in this field are likely.

So, who is liable if problems occur in the home? If a hospital has provided the ventilator and set the patient up on it, then that hospital's responsibility is likely to extend indefinitely unless this has clearly been delegated (to a home care company or another clinician). Transfer of follow up of mechanical issues to a GP or local team with no experience in ventilatory support is inappropriate. The concept of medical negligence applies to home ventilation in the same way that it applies to practices in hospital. The healthcare team should be expected to identify risks which are reasonably foreseeable (table 1) and to take action to remedy these as far as possible. However, the law does recognise that some events are either not foreseeable or beyond the bounds of reasonably practical preventative measures. ${ }^{10}$ Each case is decided on the individual circumstances in the light of expert opinion. Where guidelines and protocols are available-for example, manufacturers' recommendations for ventilator servicing-they should be followed unless there are specific reasons to the contrary, which should be noted. ${ }^{10}$

Farré et al are correct in concluding that attention to detail in setting up and servicing of ventilatory equipment in the home is essential. Similar attention directed towards education and competency training of patients, carers, and families and continuing support in the home are just as important. Patient shared records should facilitate the exchange of key information such as the ventilator type, settings, interfaces, tracheostomy size, usual blood gas measurements, and advance directives with all members of the care team.

Finally, it is usually advisable to explain carefully to the patient and family the risks associated with home ventilation and the steps taken to minimise (but necessarily not totally abolish) them. With sensible arrangements in place, most willingly accept this trade off as home care, where possible, is far preferable to long term hospital care.

Thorax 2006;61:369-371.

doi: $10.1136 /$ thx.2005.055566

Correspondence to: $\operatorname{Dr} A$ K Simonds, Consultant in Respiratory Medicine, Royal Brompton Hospital, Sydney Street, London, SW3 6NP, UK; a.simonds@rbht.nhs.uk 
Competing interests: The author has received research grants from ResMed UK and Breas Medical.

\section{REFERENCES}

1 Towlson S. Power cut kills man on home ventilator. The Times 14 August 2000.

2 Lloyd-Owen SJ, Donaldson GC, Ambrosino N, et al. Patterns of home mechanical use in Europe: results from the Eurovent survey. Eur Respir J 2005;25:1025-31.

3 Margolan H, Fraser J, Lenton S. Parental experience of services when their child requires long term ventilation. Implications for commissioning and providing services. Child: Care, Health and Development 2004;30:257.

4 Leger P. Organization of long-term mechanical ventilation in Europe. In: Simonds AK eds. Non-invasive respiratory support. A practical handbook. London: Arnold, 2001:271-81.

5 Srinivasan S, Doty SM, White TR, et al. Frequency, causes and outcome of home ventilator failure. Chest 1998;114:1363-7.

6 Farré R, Navajas D, Prats E, et al. Performance of mechanical ventilators at the patient's home: a multicentre quality control study. Thorax 2006:61:400-4.

\section{Collateral ventilation}

\section{E J Cetti, A J Moore, D M Geddes}

\section{Understanding collateral ventilation is probably central to planning new bronchoscopic techniques for treating emphysema}

$\mathrm{T}$ he phenomenon of collateral ventilation in the human lung is defined as "the ventilation of alveolar structures through passages or channels that bypass the normal airways". This phenomenon seems to be prominent in emphysema and is emerging as a key issue for those working in the new and exciting field of bronchoscopic techniques for treating emphysema.

The existence of channels within the lungs through which such collateral flow could occur was realised a century ago, ${ }^{1}$ but it was not until the 1930s that the possible significance of this flow was recognised. ${ }^{2}$ This significance was largely ignored by physiologists and physicians alike, ${ }^{3}$ apart from a select band of investigators in the 1960s and 1970s. ${ }^{4-7}$ However, with the emergence of new bronchoscopic techniques for treating emphysema, the phenomenon of collateral ventilation has gained a renewed importance and the paper by Higuchi et $a l^{8}$ in this issue of Thorax casts some welcome light on the issue of collateral ventilation in the emphysematous lung.

\section{ANATOMICAL, PHYSIOLOGICAL AND CLINICAL EVIDENCE FOR THE EXISTENCE OF COLLATERAL VENTILATION}

In order for collateral flow of air to occur within the lungs, there must exist collateral channels with a pressure gradient across them. Candidate pathways for collateral ventilation include interalveolar pores, ${ }^{9}$ accessory bronchiole-alveolar communications, ${ }^{10}$ and accessory respiratory bronchioles connecting bronchiole to bronchiole. ${ }^{4}$ As Higuchi et $a l^{8}$ point out in this issue of Thorax, interlobar collateral flow across fissures has been demonstrated, and while this may be via some of the above pathways, in the context of lung destruction by emphysema new channels may develop. The resistance to collateral flow in human lungs has been measured and found to be 50 times greater than the resistance to flow through the normal airways. ${ }^{511}$ It therefore seems that collateral ventilation cannot exist to any significant degree in normal airways. However, the resistance to collateral flow is markedly reduced in emphysema to such an extent that the resistance to flow in segmental airways (increased by expiratory collapse and mucus plugging) can actually be greater than the resistance to flow through the collateral pathways. ${ }^{512}$ Significant airflow obstruction is a hallmark of emphysema and this leads to areas of uneven ventilation resulting in the creation of pressure gradients within the lung. Low resistance collateral channels can therefore exist in emphysema with pressure gradients across them-a situation likely to lead to significant collateral ventilation.

The fact that collateral ventilation does occur can be inferred by some simple observations. In 1947 Baarsma noticed that total lower lobe bronchus occlusion following foreign body aspiration by a patient did not lead to any atelectasis. He hypothesised that air must have been ventilating the occluded segments via collateral channels and
7 Lechtzin N, Weiner CM, Clawson L. A fatal complication of noninvasive ventilation. N Engl J Med 2001;344:533.

8 Miyasaka K, Suzuki Y, Sakai $H$, et al. Interactive communication in high-technology home care: videophones for pediatric ventilatory care. Pediatrics 1997.99.El.

9 Goldberg Al. Noninvasive mechanical ventilation at home: building upon the tradition. Chest 2002; 121:321-4.

10 Branthwaite MA. Ethical and medico-legal aspects of assisted ventilation. In: Simonds AK eds. Non-invasive respiratory support: a practical handbook. London: Arnold 2001:282-91. went on to demonstrate segmental collateral flow experimentally. ${ }^{13}$ A similar recognised phenomenon is the lack of lobar collapse in emphysema when total lobar occlusion occurs due to tumour, and the technique described by Higuchi $e^{2} \mathrm{al}^{8}$ is an extension of a well documented anaesthetic/surgical phenomenon. When an emphysematous lung is ventilated it is often observed that selective lobar intubation does not lead to collapse of the other lobes - that is, air must be passing into these other lobes via collateral channels.

\section{THE IMPORTANCE OF COLLATERAL VENTILATION IN DISEASE}

Collateral ventilation does not seem to exist in infancy but develops later in life and to a much greater degree in emphysema. ${ }^{14}$ As emphysema is "an increase beyond the normal in the size of the air spaces distal to the terminal bronchiole, accompanied by destruction of their walls", ${ }^{15}$ it is possible to hypothesise how the disease process might lead to the formation of collateral channels. Perhaps the destruction of the alveolar walls together with changes in mechanical strain $^{5}{ }^{6}$ opens up new channels for flow or simply causes enlargement of existing channels, thereby reducing their resistance.

So, if emphysema leads to increased collateral ventilation, what are the consequences? In an area of lung that is completely obstructed, without collateral ventilation, alveolar gas tensions within the obstructed area rapidly equilibrate with mixed venous blood, no further gas exchange occurs, alveolar gas is absorbed, and atelectasis develops. ${ }^{7}$ It is easy to see that collateral ventilation can prevent atelectasis in the setting of airflow obstruction, but does this have any significant functional benefits? The fact that collateral ventilation is of functional importance is supported by the observation that horses do not have collateral ventilation and tolerate obstructive lung diseases very poorly while dogs have a substantial degree of collateral ventilation and 